\title{
Implications of the integration of renewable energies into the electricity market of Greece
}

\author{
U. Bachhiesl OVE, P. Kakavas, G. Feichtinger, R. Gaugl
}

\begin{abstract}
The main purpose of this paper is a comprehensive investigation of the Greek electricity production and transmission system with a focus on the integration of renewable energy sources. A techno-economic model of the Continental European electricity sector called ATLANTIS is used to analyse the development of the Greek power system. Several different projections-including national, ENTSO-E and European scenarios-have been investigated and the officially published national development strategy of Greece until 2027 has been chosen for the simulation. Starting with the modelling of the technical system, that considers a pre-defined development path for the power plant park and the transmission grid, several techno-economic investigations are performed. These include the effects of an increasing electricity demand on the electricity production with respect to several technologies, the imports, the load flows and the $\mathrm{CO}_{2}$ emissions. Additionally, the age structure and the value of the power plant park are analysed. The results illustrate a remarkable shift from a fossil fuel dominated electricity structure to an electricity system with a high share of renewable energies. The integration of the wind power and solar/PV production capacities requires a corresponding enhancement of the Greek transmission grid including several new cross-border connections to the neighbouring countries. Therefore, all important transmission grid projects based on the TYNDP and the national grid operator have been included in the physical transmission system, which covers long distance connections between the islands and the mainland as well as connections between the islands themselves by using also the HVDC technology. Furthermore, it is shown that due to the reduced lifetime of the RES technologies compared to the fossil-fuelled and the hydro power plants the up-coming re-investment cycles have to be planned carefully. Finally, the paper closes with a comprehensive discussion of the outcomes and gives an outlook of the ongoing and the future works, which cover e.g. a stronger linkage of the whole Mediterranean electricity systems to the European transmission grid according to a European energy strategy.
\end{abstract}

Keywords: electricity economics; transmission grid; power plant park; renewable energy; $\mathrm{CO}_{2}$ emissions; capital stock; load-flow; ATLANTIS simulation model, Greece

\section{Introduction}

The reduction of greenhouse gas (GHG) emissions due to reduce the climate change is of utmost importance in the energy sector. Since the first energy strategy of the European Union (EU) climate protection has been one of the major pillars also in the following strategies. Aside the well-known 2020 targets [1], the EU has also already formulated targets for the energy sector up to the year 2030 [2] and even a long-term perspective up to the year 2050 [3]. Main elements of the energy strategies comprise e.g. energy efficiency measures as well as the rise of the share of renewable energies (RES) in the energy system. Until 2030 the EU wants to realise the following targets that include (i) a $40 \%$ cut in greenhouse gas emissions compared to 1990 levels, (ii) a $27 \%$ share of renewable energy consumption and (iii) $27 \%$ energy savings compared to the business-as-usual scenario. Moreover, the long-term goal until 2050 foresees a reduction of the GHG-emissions up to $85-90 \%$ until 2050 , which means nearly a decarbonisation of the energy system.

These targets have to be broken down to the national level for every single member state. This paper deals with the implications of the integration of renewable energies into the electricity market of Greece. Up to the year 2020 in total $18 \%$ of total energy consumption should be produced by renewable sources. Regarding the development of the Greece electricity economy, several targets and development scenarios exist. The leading electricity company of Greece-Public Power Cooperation—developed a strategy until the year 2027 [4, 5]. The European Network of Transmission System Operators for Electricity (ENTSO-E) published four visions for the devel- opment of the European electricity system until the year $2030[6,7]$. In 2016, the EU published a reference scenario for the development of the European energy sector until the year 2030 and 2050 [8].

Figure 1 compares the national strategy until 2027 and several other development scenarios with deviating target years for the Greek electricity sector as a breakdown of the net installed capacities with respect to the production technologies.

\section{Methodical approach}

The Institute of Electricity Economics and Energy Innovation/Graz University of Technology (IEE) developed a techno-economic model of the electricity sector in Continental Europe (former area of the UCTE) - a synchronous power transmission area with a net installed capacity of about $750 \mathrm{GW}$ by the end of year 2011 and annual consumption of approximately 2.600 TWh in year 2011. At the core of the model is a database, which includes all necessary elements of the physical system. That is the synchronous transmission grid at different voltage levels ( $400 \mathrm{kV}, 220 \mathrm{kV}$ and selected $110 \mathrm{kV}$ ), more than 25.000 individual power plants that are characterized by

Paper submitted for the CIGRE Session 2018, SC C5, Paris, France, August 26-31, 2018.

BachhiesI , Udo, Institute of Electricity Economics and Energy Innovation, Graz University of Technology, Inffeldgasse 18/II, 8010 Graz, Austria (E-mail: bachhies|@tugraz.at); Kakavas, P., University of Patras, Patras, Greece; Feichtinger, G., Graz University of Technology, Graz, Austria; Gaugl, R., Graz University of Technology, Graz, Austria 


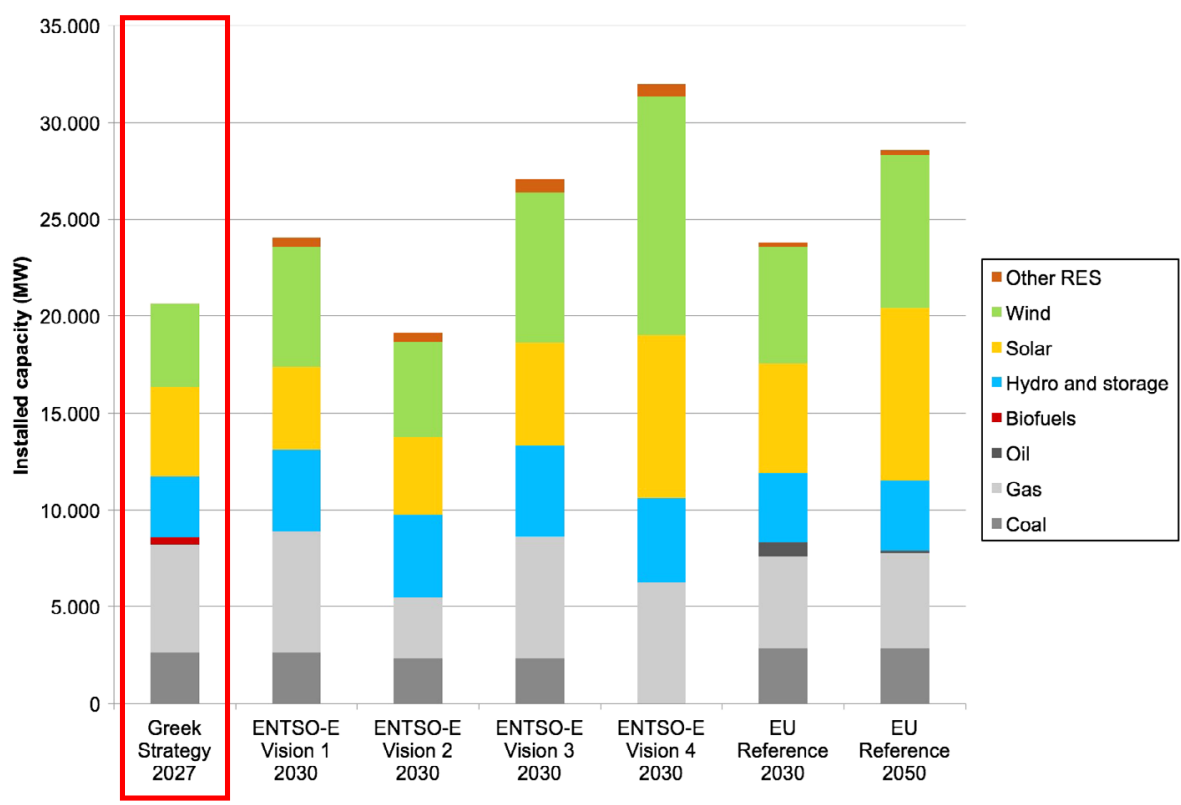

Fig. 1. Comparison of several published development scenarios for the Greek electricity sector (Color figure online)
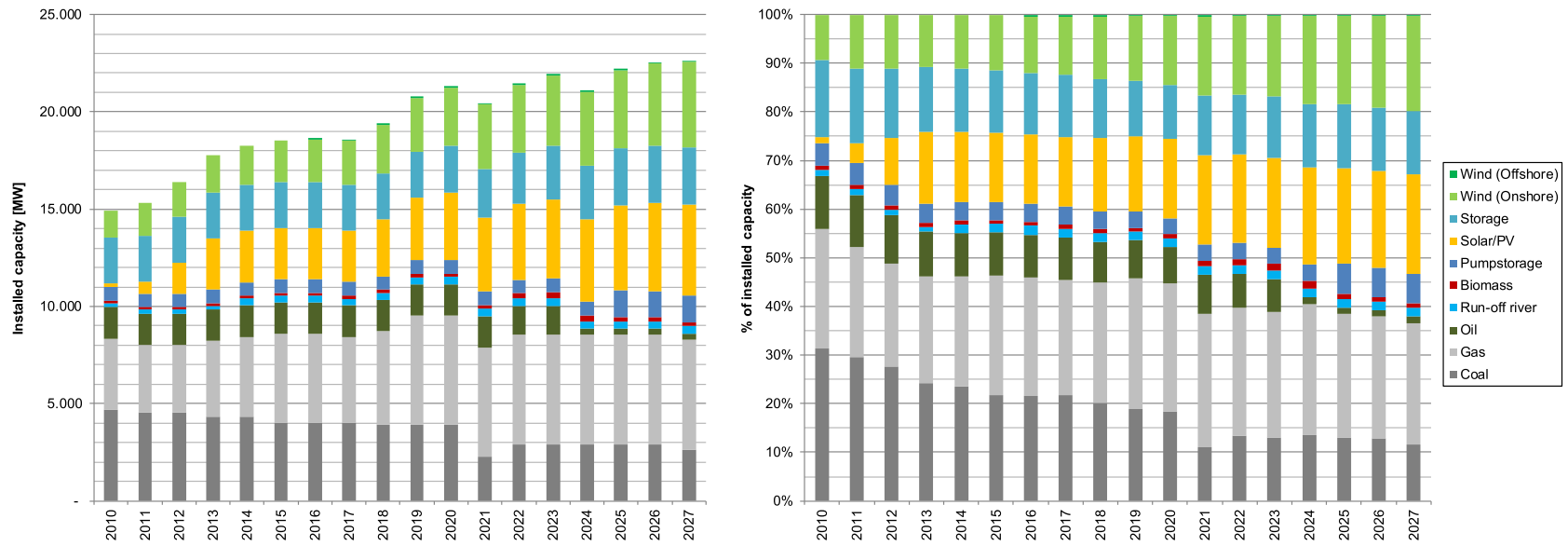

Fig. 2. Development of the total installed power plant capacity in Greece (Color figure online)

different properties ${ }^{1}$ and electricity demand ${ }^{2}$ of households and industry, which is geographically downscaled and distributed to grid nodes. Electricity trade is covered by (i) a zonal pricing market model, which performs an implicit pan-European market coupling between countries based on net transfer capacities (NTC) and (ii) a redispatch model, which applies a direct current optimized power flow (DC-OPF) algorithm $[9,10]$

\section{The electricity system of Greece}

ATLANTIS has been used to simulate and analyse the future development of the electricity system of Greece. Based on an in-deep investigation of the present Greek electricity system the model of the Greek electricity system has been redefined. Taking into ac-

\footnotetext{
${ }^{1}$ The most important characteristics are the nominal capacity, commissioning date, fuel type, geographical location, feed-in node, efficiency level, operating life time, monthly productions factors and standard capacity.

${ }^{2}$ Yearly electricity consumption is represented by an hourly time series.
}

count the different present existing strategies, targets and scenarios, a base scenario for Greece has been built until the year 2027. This base scenario considers future potentials especially for PV and wind power. Based on an intensive literature and internet research along with direct information of relevant Greek institutions the data of the Greek electricity system has been updated [11-13]. Special emphasis has also been put on the high voltage electricity grid [14] and the development of renewable energies-especially wind power and photovoltaics-in Greece [15-17].

Figure 2 shows the yearly expansion of the power plant production technologies according to the Greek national strategy until 2027. The increase in total production capacity from 15 GW in 2010 to almost 23 GW in 2027 is associated with a strong increase in RES production technologies (mainly wind power and solar/PV) as well as a switch from coal/oil to gas fired power stations. Overall, the share of RES capacities increases significantly to more than $60 \%$ of the available production capacities.

The geographical distribution of the technology-specific power plant park in 2027 is illustrated in Fig. 3. The expansion of wind 

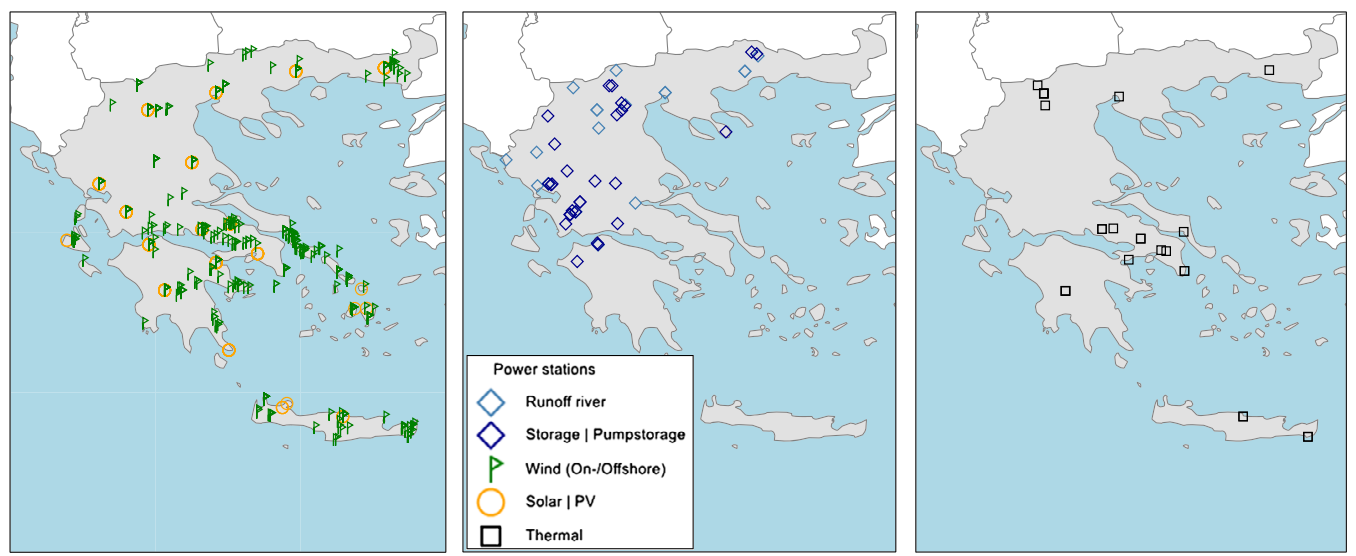

Fig. 3. Power plant park for RES (left), hydro (centre) and fossil fuels (right) for Greece in 2027 (Color figure online)
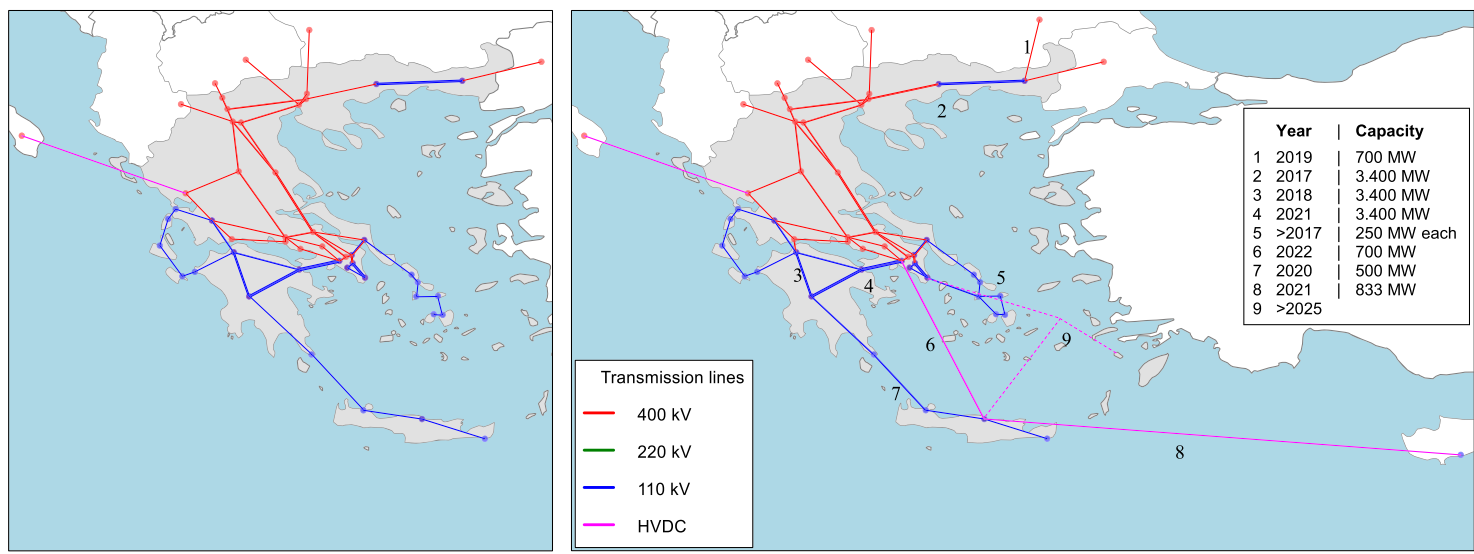

Fig. 4. Transmission grid of Greece in 2010 (left) (in 2010, the connections between Crete and the mainland and within the Aegean Sea are dummy-lines with a very low transmission capacity and a high resistance to prevent isolated islands that slow down the simulation) and 2027 (right) (Color figure online)

power ${ }^{3}$ and solar/PV (left) is distributed within the evaluated areas with high production potentials, which are generally located in the Aegean Sea and on the island of Crete $[15,16]$. Hydro power stations are placed along the major rivers, whereas the storage and pumped storage stations are located in the mountainous regions in Greece (centre). The fossil-fuelled power stations (right) are built around the areas with high electricity demand like Thessaloniki and Athens as well as on several islands in the Aegean Sea and Crete. ${ }^{4}$

Finally, the development of the Greek transmission system on the $400 \mathrm{kV}$ level goes hand in hand with the massive expansion of the RES technologies. Furthermore, it considers linkages of several islands in the Aegean Sea and of Crete to the continental electricity system as well as cross-border transmission capacities to Bulgaria and Cyprus based on HVDC and AC transmission lines. Figure 4 illustrates the corresponding grid development until 2027.

\section{The ATLANTIS simulation results}

According to the national strategy, the total electricity demand increases from 54.246 GWh in 2010 to 74.019 GWh in 2027. How-

${ }^{3}$ Wind power considers a very low share of offshore stations due to geographical locations on small islands.

${ }^{4}$ On island systems, it is assumed that oil power stations are mostly replaced by gas turbines that are more efficient.

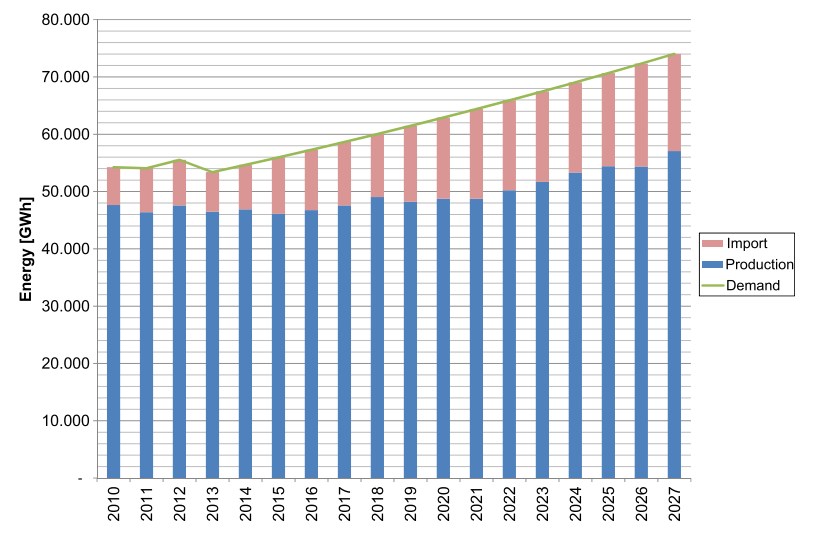

Fig. 5. Greek electricity demand, domestic production and imports (Color figure online)

ever, the ATLANTIS simulation results show only a slight increase in total domestic electricity production due to several physical restrictions, which results in continuously increasing electricity imports from some neighbouring countries. This import share raises from $12 \%$ in 2010 to $23 \%$ in 2027 (see Fig. 5). 

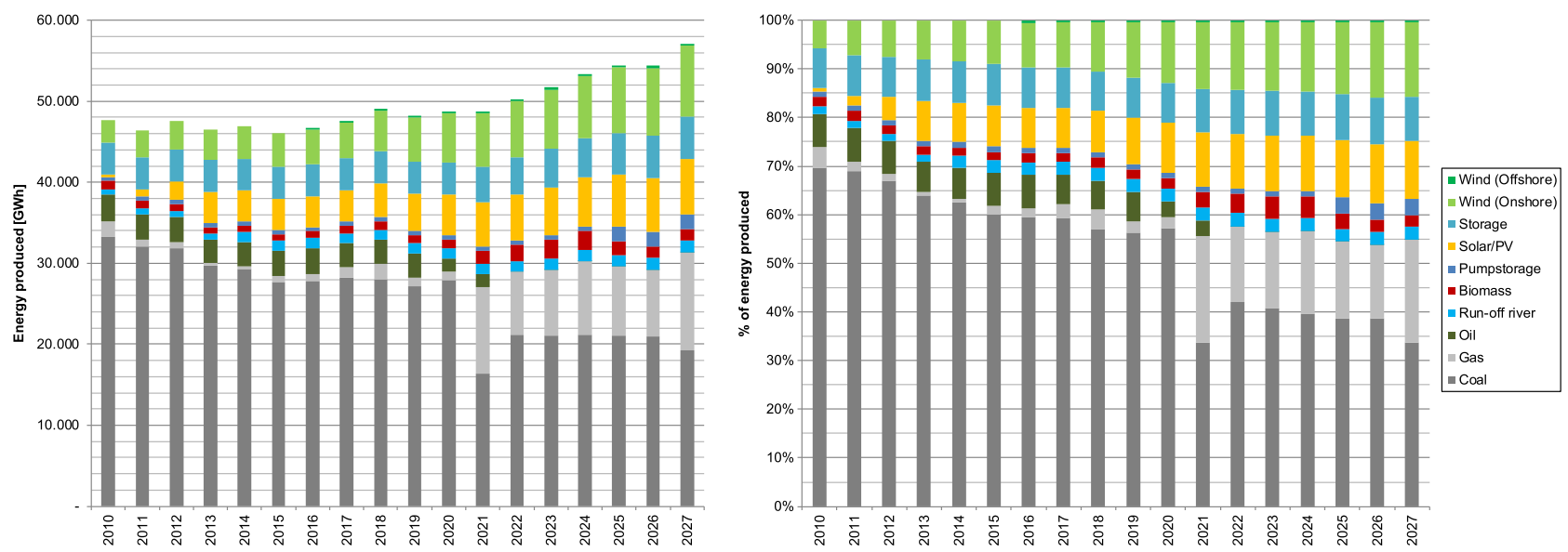

Fig. 6. Development of the produced energy by technology in Greece (Color figure online)
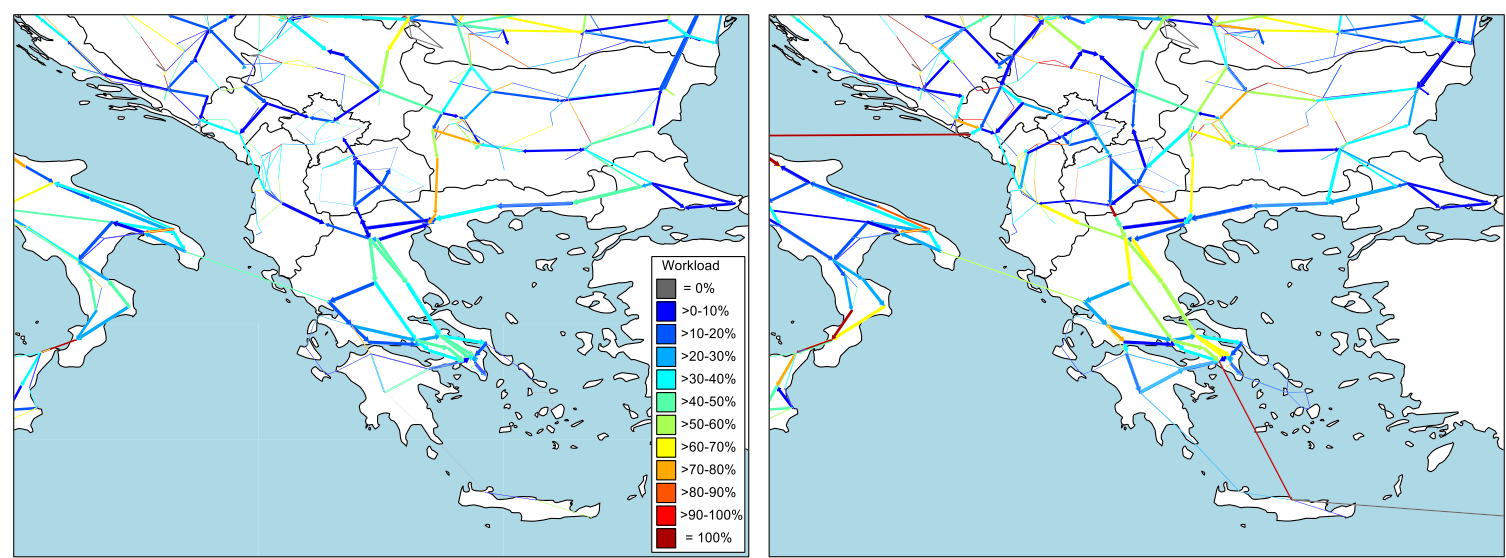

Fig. 7. Load flow at winter peak load in 2010 (left) (in 2010, the dummy transmission lines between Crete and the mainland and within the Aegean Sea are fully utilized since they are characterized by a very low transmission capacity) and 2027 (right) (Color figure online)

A breakdown of the total produced electricity with respect to the production technologies illustrates a high increase in RES production and the technology switch within the fossil-fuelled production from coal 5 /oil to gas until 2027. The shutdown of an outdated coalfired power plant increases gas-fired electricity production significantly beginning in 2021. Figure 6 undermines the development of the corresponding technology specific electricity production paths.

Figures 7 and 8 illustrate several load flow situations for the winter and summer peak load in 2010 (left) and 2027 (right). It is also highlighted that the high demand centres are located in the regions of Thessaloniki and Athens, which is reflected in the corresponding load flow directions. In 2027 the HVDC lines between the Athens region and Crete are fully utilized, which results in reduced load flows on the AC line between Peloponnese peninsula and Crete. A transmission grid expansion within the Aegean Sea reduces the critical load flows in this region and increases the reliability of electricity supply of the affected islands.

The new cross-border line to Bulgaria creates higher electricity imports, since several countries of the Balkan region tend to become electricity-exporting economies [18]. The southern region of

${ }^{5}$ The high share of electricity production by coal is a result of an assumed subsidy on domestic lignite production.
Italy imports comparably cheap electricity from Greece, because the electricity production structure in Italy is generally dependent on expensive fossil-fuelled power plants.

Figure 9 undermines the changes in the age structure of the Greek power plant park between 2010 (left) and 2027 (right). In 2010, the age of power plants is almost evenly distributed. Fossil-fuelled power plants are of a higher age and close to their corresponding technical life times (especially on the islands). Hydropower is already well developed, whereas the wind power starts to gain importance. In 2027, by contrast, the newly installed production capacities are dominated by RES technologies (especially wind power and solar/PV), gas turbines (which replace outdated coal and oil power stations) and several new hydro stations (storage and pumped storage stations).

The overall value of the capital stock of the Greek power plant park increases significantly from $5.6 \mathrm{bn}$. $€$ in 2010 up to $12.8 \mathrm{bn}$. $€$ in 2027 due to the high expansion of RES production technologies. The share of RES technologies increases from $56 \%$ up to more than $80 \%$ (thereof 30\% solar/PV, 23\% pumped storage, 15\% wind power) of the capital assets. The decommissioning of old power stations and general depreciation of the power plants cause the illustrated reductions that are shown in Fig. 10.

Finally but worth mentioning are the effects on $\mathrm{CO}_{2}$ emissions of the Greek electricity production system. Figure 11 shows the strong 

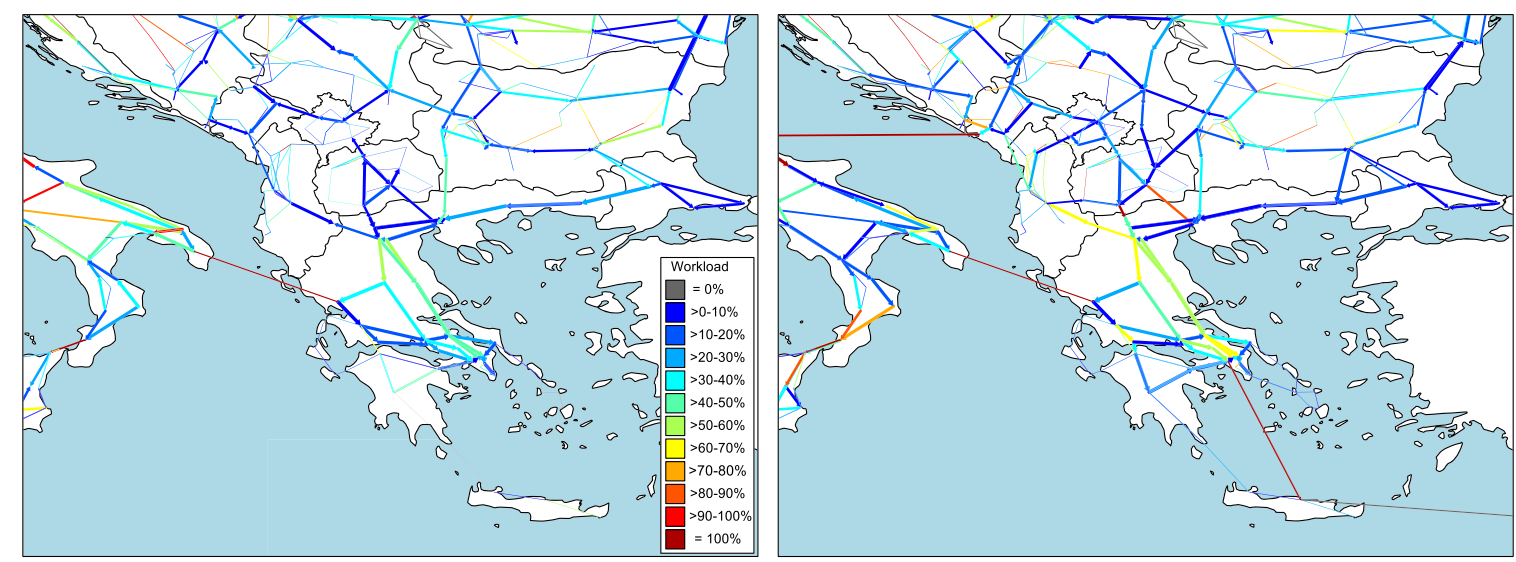

Fig. 8. Load flow at summer peak load in 2010 (left) (in 2010, the dummy transmission lines between Crete and the mainland and within the Aegean Sea are fully utilized since they are characterized by a very low transmission capacity) and 2027 (right) (Color figure online)
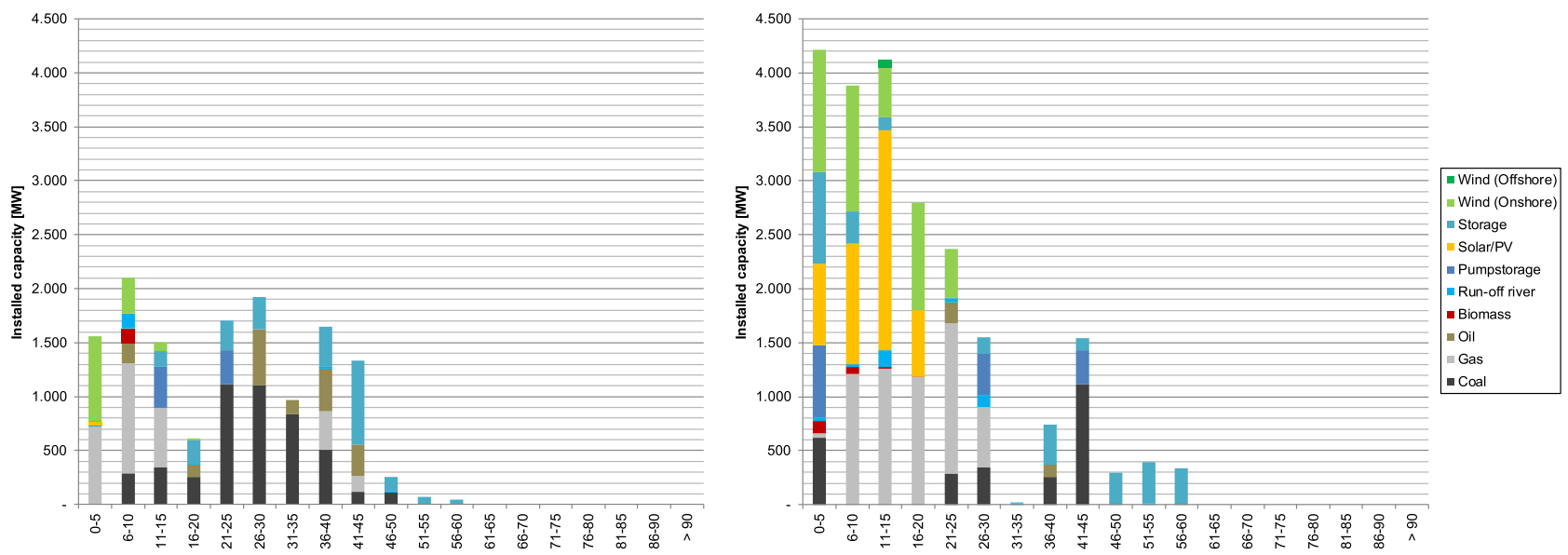

Fig. 9. Age structure of the Greek power plant park in 2010 (left) and 2027 (right) (Color figure online)
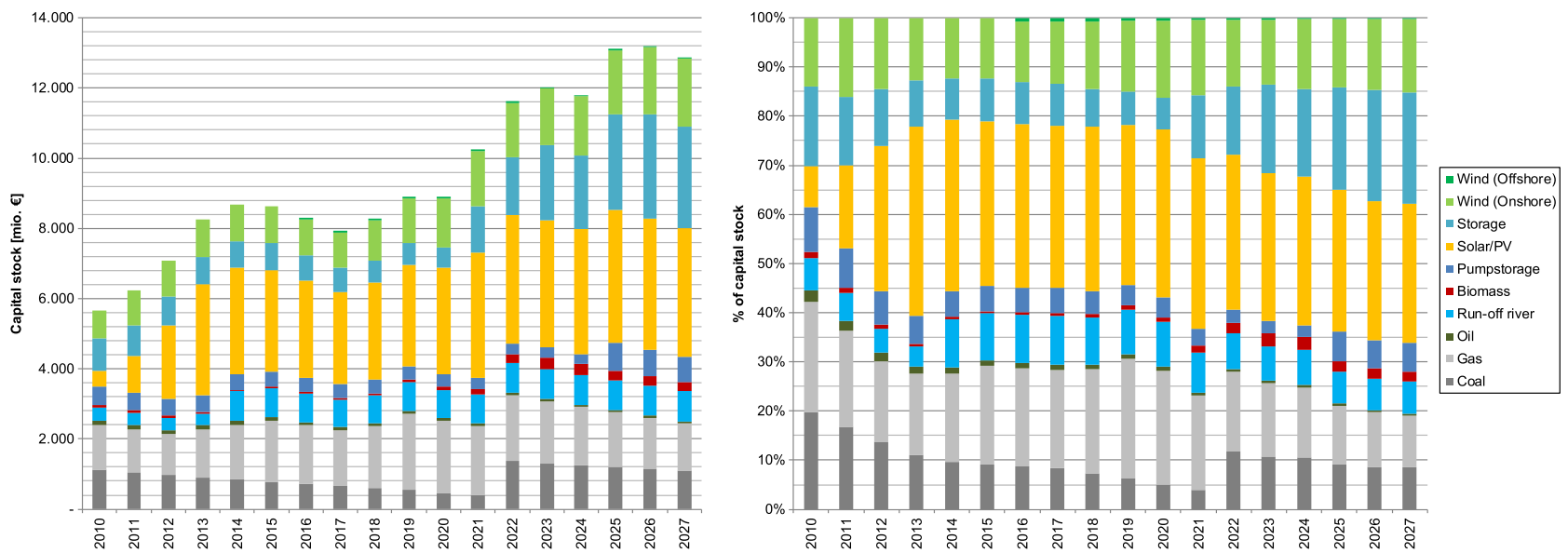

Fig. 10. Development of the capital stock of the Greek power plant park (Color figure online) 


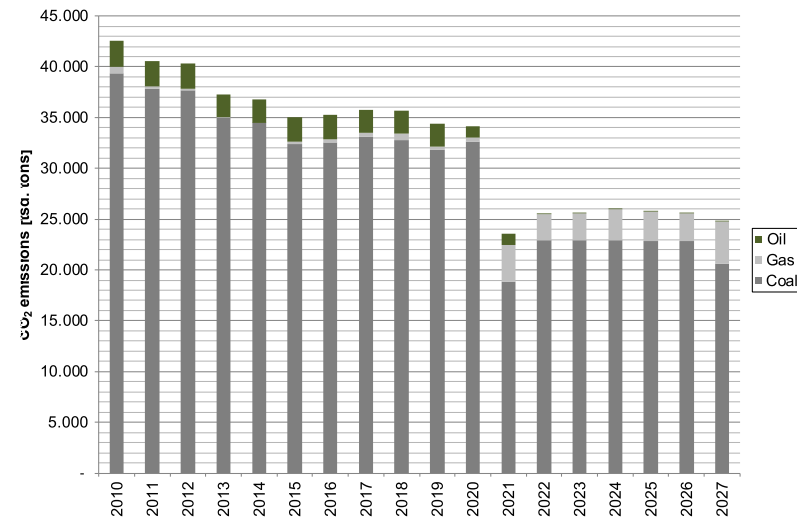

Fig. 11. Reduction of the $\mathrm{CO}_{2}$ emissions in the Greek power system (Color figure online)

impact of RES technologies in terms of a remarkable reduction in overall $\mathrm{CO}_{2}$ emissions by $42 \%$ in the Greek electricity production between 2010 and 2027. The shutdown of on old coal-fired power plant that leads to an increased utilization of gas-fired power stations ${ }^{6}$ causes a significant drop in the total $\mathrm{CO}_{2}$ emissions by $31 \%$ in 2021. Furthermore, the phase-out of the oil power plants on the main land ends by 2021, which leads to a reduction of the emissions as well.

\section{Discussion and outlook}

Based on the age structure of the Greek power plant park in 2027 and the high share of RES production technologies, a shorter and more cost-intensive re-investment cycle has to be considered in future development strategies. This is because the RES technologies have a significantly shorter technical lifetime of 25 to 30 years compared to fossil-fuelled power stations (40-50 years) and hydro power stations (60-80 years). However, several current investigations focus on the valuation of the existing capital stock of the power plant park and the overall transmission grid of ATLANTIS [19].

The future expansion of RES technologies (especially for wind power and solar/PV) after 2027 is generally located in the Aegean Sea and on Crete based on projects that have already been permitted by the Greek government. This could imply a further grid expansion in this region to integrate as much RES production as possible into the existing electricity system.

The missing HVDC-link between Crete and the Athens region through the Sea of Crete and the Aegean Sea is a new ENTSOe project that has not been considered while modelling the Greek electricity system. The consideration of this HVDC corridor would allow a better integration of existing wind power potentials in this area. Moreover, a potential transmission grid expansion on the island of Crete is required to integrate all future wind power and solar/PV projects, because the currently existing transmission lines have physical transmission limitations.

A replacement strategy for old oil-fired power plants on the Greek islands is generally missing. Such "traditional" production technologies (e.g. more efficient gas turbines) should nevertheless be considered as backup (spare) capacities for critical situations on these islands.

The inter-link between Greece and Cyprus is necessary in order to achieve the Cypriote 10\% (until 2020) and 15\% (until 2030)

${ }^{6}$ The specific $\mathrm{CO}_{2}$ emission coefficient of gas $(0.44 \mathrm{~g} / \mathrm{MWh})$ is lower compared to coal (0.8 g/MWh). electricity interconnection target [20]. So far, this inter-link has not been investigated, since the implementation of the Cypriote electricity system is currently 'work-in-progress' at the Institute of Electricity Economics and Energy Innovation/Graz University of Technology.

Furthermore, simulations with a higher demand assumption and a long-term character up to the year 2050 according to the presented development scenarios (Fig. 1) could be considered in future investigations.

Finally yet importantly, the Greek electricity system as part of the Mediterranean region is going to gain of importance due to the planned inter-connections between Greece and Cyprus as well as Cyprus and Israel. The latter could be part of a comprehensive trans-continental electricity development strategy between the European Union and Asia/Africa that integrates the Mediterranean region in the long-term. The investigation of these Mediterranean countries ${ }^{7}$ is currently 'work-in-progress' at the Institute of Electricity Economics and Energy Innovation/Graz University of Technology in order to expand the regional coverage of the ATLANTIS simulation model.

\section{Acknowledgements}

Open access funding provided by Graz University of Technology.

Open Access This article is distributed under the terms of the Creative Commons Attribution 4.0 International License (http://creativecommons.org/ licenses/by/4.0/), which permits unrestricted use, distribution, and reproduction in any medium, provided you give appropriate credit to the original author(s) and the source, provide a link to the Creative Commons license, and indicate if changes were made.

\section{References}

1. European Commission (2008): Communication from the Commission to the European Parliament, the Council, the European Economic and Social Committee and the Committee of the Regions-2020 by 2020, Europe's climate change opportunity, Brussels, 23.1.2008 COM (2008) 30 final.

2. European Commission (2014): Communication from the Commission to the European Parliament, the Council, the European Economic and Social Committee and the Committee of the Regions - a policy framework for climate and energy in the period from 2020 to 2030, Brussels, 22.1.2014 COM (2014) 15 final.

3. European Commission (2011): Communication from the Commission to the European Parliament, the Council, the European Economic and Social Committee and the Committee of the Regions-A Roadmap for moving to a competitive low carbon economy in 2050", Brussels. 8.3.2011 COM(2011) 112 final.

4. Admie (2016): Ten year development plan 2016-2027. http://www.admie.gr/ fileadmin/groups/EDAS DSS/MASM/DPA 2017-2026 Final/DPA 2017-2026.pdf.

5. Admie (2017): Power case study for the period 2017-2027. http://www.admie.gr/ fileadmin/groups/EDAS_DSS/AnaptixiSistimatos/Meleti_eparkeias_2017_2027.pdf.

6. ENTSO-e (2015): Final ten year development plan 2016 — scenarios and the consultation outcomes. https://www.entsoe.eu/major-projects/ten-year-network-developmentplan/ten\%20year\%20network\%20development\%20plan\%202016/Pages/default. aspx.

7. ENTSO-e (2015): Regional investment plan 2015—continental South East region. https://www.entsoe.eu/Documents/TYNDP\%20documents/TYNDP\%202016/rgips/ Regional\%20Investment\%20Plan\%202015\%20-\%20RG\%20CSE\%20-\%20Final. pdf.

8. European Commission (2016): The reference scenario 2016. https://ec.europa.eu/ energy/sites/ener/files/documents/ref2016 report_final-web.pdf.

9. Stigler, H., Bachhiesl, U., Nischler, G., Feichtinger, G. (2016): ATLANTIS: technoeconomic model of the European electricity sector. Cent. Eur. J. Oper. Res., 24(4), 965-988. https://doi.org/10.1007/s10100-015-0413-8.

10. Feichtinger, G. (2017): A multi-regional input-output framework to evaluate European energy policies. Doctoral thesis, University of Graz, Austria.

11. Admie (2016): Map. http://www.admie.gr/fileadmin/groups/EDAS_DSS/MASM/DPA_ 2017-2026_Final/DPA_2017-2026_CHartis.pdf.

12. CIGRÉ (2017): The electric power system—Greece. http://www.cigre.org/var/cigre/ storage/original/application/c5729776471a98524c7b244696a2cc95.pdf.

\footnotetext{
${ }^{7}$ These countries are Marocco, Algeria, Tunisia, Libya, Egypt and Israel.
} 
13. International Energy Agency (2011): Energy policies of IEA countries-Greece 2011 review. https://www.iea.org/publications/freepublications/publication/energy-policiesof-iea-countries-greece-2011-review.html.

14. Official Journal of the European Union, Current Projects of Common Interest (2015): Regulation. http://eur-lex.europa.eu/legal-content/EN/TXT/PDF/?uri=OJ:JOL_2016 019_R_0001\&from=EN.

15. Greek Scientific Association of Wind Energy (2017): http://eletaen.gr/.

16. Hellenic Association for Photovoltaic Companies (2017): Hellenic Association for Photovoltaic Companies. http://helapco.gr/en/the-greek-pv-market/.

17. Manolopoulos, D., Kitsopoulos, K., Kaldellis, J. K., Bitzenis, A. (2016): The evolution of renewable energy sources in the electricity sector of Greece. Int. J. Hydrog. Energy, 41(29), 12659-12671. https://doi.org/10.1016/j.ijhydene.2016.02.115.
18. Gaugl, R., Lekic, A., Perani, B., Bachhiesl, U. (2018): Future scenarios for the development of the electricity economies within the Balkan region. In Symposium Energieinnovation, Graz, Austria.

19. Ochensberger, P. Stigler, $\mathrm{H}$. (2017): What is it worth? Determining the capital stock of European run-of-river and threshold hydropower plants. In International Expert Meeting Komunalna Energetika, Maribor, Slovenia.

20. European Commission Expert Group (2017): Electricity interconnection targets. https://ec.europa.eu/energy/en/topics/infrastructure/projects-common-interest/ electricity-interconnection-targets. 